\title{
Negative exploration for pyloric stenosis - Is it preventable?
} Dhanya Mullassery*1, Sreelakshmi Mallappa1, Raheel Shariff1, Ross J Craigie ${ }^{1}$, Paul D Losty ${ }^{1}$, Simon E Kenny ${ }^{1}$, David Pilling ${ }^{2}$ and Colin T Baillie ${ }^{1}$

\author{
Address: ${ }^{1}$ Department of Paediatric Surgery, The Royal Liverpool Children's Hospital (Alder Hey), Eaton Road Liverpool L12 2AP, UK and \\ 2Department of Paediatric Radiology, The Royal Liverpool Children's Hospital (Alder Hey), Eaton Road Liverpool L12 2AP, The University of \\ Liverpool, UK \\ Email: Dhanya Mullassery* - dhanya.mullassery@nhs.net; Sreelakshmi Mallappa - sree.mallappa@rlc.nhs.uk; \\ Raheel Shariff - Raheel.shariiff@rlc.nhs.uk; Ross J Craigie - dhanya.mullassery@nhs.net; Paul D Losty - Paul.losty@liverpool.ac.uk; \\ Simon E Kenny - Simon.kenny@liverpool.ac.uk; David Pilling - David.pilling@rlc.nhs.uk; Colin T Baillie - colin.baillie@rlc.nhs.uk \\ * Corresponding author
}

Published: 24 September 2008

BMC Pediatrics 2008, 8:37 doi:10.1186/147/-2431-8-37

This article is available from: http://www.biomedcentral.com/I47I-243I/8/37

(c) 2008 Mullassery et al; licensee BioMed Central Ltd.

This is an Open Access article distributed under the terms of the Creative Commons Attribution License (http://creativecommons.org/licenses/by/2.0), which permits unrestricted use, distribution, and reproduction in any medium, provided the original work is properly cited.
Received: 10 January 2008

Accepted: 24 September 2008

\begin{abstract}
Background: The diagnosis of infantile hypertrophic pyloric stenosis (IHPS), although traditionally clinical, is now increasingly dependent on radiological corroboration. The rate of negative exploration in IHPS has been reported as $4 \%$. The purpose of our study was to look at elements of supportive clinical evidence leading to positive diagnosis, and to review these with respect to misdiagnosed cases undergoing negative exploration.
\end{abstract}

Methods: All infants undergoing surgical exploration for IHPS between January 2000 and December 2004 were retrospectively analysed with regard to clinical symptoms, examination findings, investigations and operative findings.

Results: During the study period, 343 explorations were performed with a presumptive diagnosis of IHPS. Of these, 205 infants $(60 \%)$ had a positive test feed, $269(78 \%)$ had a positive ultrasound scan and $175(55 \%)$ were alkalotic $(\mathrm{pH} \geq 7.45$ and/or base excess $\geq 2.5)$. The positive predictive value for an ultrasound (US) diagnosis was $99.1 \%$ for canal length $\geq 14 \mathrm{~mm}$, and $98.7 \%$ for muscle thickness $\geq 4 \mathrm{~mm}$.

Four infants (I.I\%) underwent a negative surgical exploration; Ultrasound was positive in 3 , and negative in I(who underwent surgery on the basis of a positive upper $\mathrm{Gl}$ contrast). One US reported as positive had a muscle thickness $<4 \mathrm{~mm}$. Two false positive US were performed at peripheral hospitals. One infant had a false positive test feed following a positive ultrasound diagnosis. Two infants had negative test feeds.

Conclusion: A I\% rate of negative exploration in IHPS compares favourably with other studies. However potential causes of error were identified in all 4 cases. Confident diagnosis comprises a combination of positive test feed and an 'in house US' in an alkalotic infant. UGI contrast study should not be used in isolation to diagnose IHPS. If the test feed is negative, strict diagnostic measurements should be observed on US and the pyloric 'tumour' palpated on table under anaesthetic before exploration. 


\section{Background}

Before the widespread introduction of US in 1977 [1], the diagnosis of infantile hypertrophic pyloric stenosis (IHPS) was made on the clinical finding of a palpable pyloric mass. An additional suggestive feature in the vomiting child is the characteristic biochemical picture of hypochloraemic hypokalaemic metabolic alkalosis. Although the decreasing incidence of these features (palpable mass and typical biochemical picture) have been attributed to earlier diagnosis and surgical referral [2-4], ultrasound evaluation is often obtained even before attempting a test feed [5] in many infants. The reported diagnostic accuracy of ultrasound in IHPS is variable and operator dependent [6-8]. This study aims to determine the incidence of negative exploration (NL) following a presumptive diagnosis of pyloric stenosis, and to identify factors leading to surgery.

\section{Methods}

The hospital case records of 343 patients who underwent surgical exploration with a presumptive diagnosis of IHPS at the Royal Liverpool Children's Hospital between January 2000 and December 2004 were reviewed. Demographics, clinical findings, preoperative imaging, duration of symptoms, biochemical investigations and operative findings were collected from several sources (case notes, transfer letters, operative reports and computer records). During the period of the study, a defined protocol for diagnosis of IHPS was not used at our centre, and surgical exploration was performed at the discretion of the registrars and consultants based on a variable combination of test feed, US and presence of alkalosis. All recorded test feeds were performed by the duty surgical registrar. A nasogastric tube was used to aspirate the stomach prior to commencing test feeding with the infant in the mother's arms. A test feed was considered positive if it was possible to palpate a pyloric 'olive' during the test while the infant was orally fed with $<50 \mathrm{mls}$ of milk or dioralyte. Visible peristalsis in isolation was not criterion for a positive test feed, as it may be present in gastric or intestinal obstruction. The majority ( $85.5 \%)$ of positive ultrasound reports were accompanied by measurements of canal dimensions. At our centre, an US scan was considered to confirm pyloric stenosis if the length of the pyloric canal exceeded $14 \mathrm{~mm}$ and the muscle thickness $\geq 4 \mathrm{~mm}$. Alkalosis was defined as a serum $\mathrm{pH} \geq 7.45$ and/or base excess (BE) $\geq 2.5$.

\section{Results}

\section{Demographics}

The mean age at surgery of the study population (296 male and 47 female) was 35 days (range 3-150) and the mean duration of symptoms was 9.5 days (range 1-56).

\section{Test feed}

A test feed was documented in 219/343 (64\%) of infants. Of these, 205 (93.6\%) were positive. Eighty (38.5\%) children underwent pyloromyotomy without US, purely on the basis of a positive test feed.

\section{Radiology}

An US scan was done in 270/343 (79\%) children. All but one of the 270 US scans were reported to be positive. Sixty four of these were done in another referring hospital prior to transfer. In 39 studies (including 13 performed at our hospital), the scan was reported as showing pyloric stenosis, without stating the diagnostic measurements. Among the US scans reported as positive, 230 infants had a pyloric canal length more than $14 \mathrm{~mm}$, and 220 had muscle thickness of at least $4 \mathrm{~mm}$. The positive predictive value for an ultrasound (US) diagnosis was $99.1 \%$ for canal length $\geq 14 \mathrm{~mm}$, and $98.7 \%$ for muscle thickness $\geq 4$ $\mathrm{mm}$. One hundred and twenty four infants had an US diagnosis without a test feed, and 14 had a negative test feed but positive US diagnosis.

\section{Biochemical analysis}

The case notes and transfer letters from peripheral hospitals were reviewed for evidence of biochemical abnormalities consistent with a diagnosis of pyloric stenosis. One hundred and seventy five (55\%) patients had obvious evidence of alkalosis (defined as $\mathrm{pH} \geq 7.45$ or $\mathrm{BE} \geq 2.5$ ). Hypokalemia $(\mathrm{K}<4)$ was observed in 38 infants and hypochloremia $(\mathrm{Cl}<95)$ in 32 .

\section{Misdiagnoses}

Four infants were found to have a normal pylorus at laparotomy (NL) (Table 1). All four patients underwent a minimal myotomy of the normal pylorus. A 'minimal myotomy' is division of the muscle layer while ensuring mucosal integrity (confirmed by an air injection via the nasogastric tube). We have previously seen patients with absence of US features of IHPS who have subsequently developed the radiological features within 3-4 days. The observation of this phenomenon of 'IHPS in evolution' provided the rationale for performing minimal myotomy in these children.

Infant 1 had negative test feed and a positive ultrasound with normal blood gases. Postoperatively, he developed a wound infection which was treated with oral antibiotics. He was shown to have gastro oesophageal reflux (GOR), which responded to treatment.

Infant 2 was felt to have a palpable pyloric mass after a positive ultrasound from a peripheral hospital. His gases were normal. His vomiting subsided post-operatively after a few days of careful feeding. 
Table I: Patients who had a negative laparotomy (NL)

\begin{tabular}{|c|c|c|c|c|c|c|c|}
\hline \multirow[t]{2}{*}{ Patient no } & \multirow[t]{2}{*}{ Test feed } & \multirow[t]{2}{*}{ UGI } & \multicolumn{3}{|l|}{ Ultrasound } & \multicolumn{2}{|c|}{ Biochemistry } \\
\hline & & & Report & Canal length & Muscle thickness & $\mathrm{pH}$ & $\mathrm{BE}$ \\
\hline 1 & Negative & - & Positive & 20 & 4 & 7.38 & -0.1 \\
\hline 2 & Positive & - & Positive* & 17 & 4 & 7.42 & -0.4 \\
\hline 3 & Not done & - & Positive* & 18 & 2.1 & 7.46 & 4.5 \\
\hline 4 & Negative & positive & Negative & 10 & 2.2 & 7.44 & 5.2 \\
\hline
\end{tabular}

UGI - Upper GI contrast study.

Results which do not reach diagnostic criteria in bold italics.

* US done in a peripheral hospital

Infant 3 had an ultrasound reported from the peripheral hospital as positive, but with a muscle thickness of only $2.1 \mathrm{~mm}$. A test feed was not done. She had an alkalotic picture on blood gases. She collapsed with necrotising enterocolitis 3 days after the surgery and died (without a further laparotomy).

Infant 4 had negative results on both test feed and ultrasound. A diagnosis of pyloric stenosis was based on an upper gastrointestinal contrast study performed at another hospital. He was later diagnosed to have GOR which settled with medical treatment.

\section{Discussion and conclusion}

The typical clinical diagnosis of IHPS is based on the finding of a palpable pyloric 'tumour' in an infant aged between 1 and 6 weeks with a history of vomiting and weight loss. "Projectile" vomiting is not discriminating, as this symptom may feature in any vomiting infant and is common in GOR [9]. Traditionally, a positive test feed established the diagnosis $[2,9,10]$. However, exclusive reliance on the test feed for diagnosis in pyloric stenosis is associated with false positive rates of $3-14 \%$ and false negative rates of $18-33 \%[6,9,11]$. The reported decline in the use of the test feed $[2,3,7]$ is supported by our finding that $39 \%$ of the infants in our study did not have the test. The reduced reliance on test feed for diagnosis inevitably diminishes clinical acumen for this mode of diagnosis. In our study, one of the patients in the NL group had a false positive test feed, after a positive ultrasound diagnosis from the referring hospital. The pyloric 'tumour' can be difficult to palpate in the early stages. Interestingly, the role of an element of 'suggestibility' has been reported previously, that if the examiner was aware of a positive US before doing a test feed, the success in palpating the pyloric 'tumour' increased to $46 \%$, compared to the $26 \%$ when the examiner was unaware of the positive US [11].

Ultrasonography is now a well established diagnostic modality for the diagnosis of pyloric stenosis. Since its first description by Teele and Smith in 1977 [1], the diag- nostic criteria for pyloric stenosis on US have been made more stringent [12-14] in an attempt to minimise false positive results and unnecessary surgery. A combination of definite measurements of canal length and muscle thickness is now expected for confident ultrasonographic diagnosis. Reported over-reliance on US [2,3,15-17] by clinicians has also been attributed earlier presentation of infants and the pressure on early diagnosis in the modern cost-conscious health service [3]. Accuracy in measuring the dimensions of the pylorus is critically dependent on the experience of the individual sonographer, who should see sufficient number of cases to maintain expertise [7]. Currently in the UK NHS, paediatric surgery has become mainly restricted to tertiary centres, and hence with this move, the diagnostic capabilities and experts in paediatric surgical conditions are concentrated in tertiary centres. With these provisions, we now prefer an 'in-house' US for diagnosis of IHPS, defined as one performed by a tertiary centre paediatric radiologist who performs these scans routinely. An upper GI contrast study is not reliable in the diagnosis of IHPS, as it can mistake pylorospasm for canal obstruction [18]. In cases of diagnostic uncertainty between IHPS and GOR, a contrast swallow can help to establish diagnosis of GOR. However, it is clinically difficult to justify using a contrast study in cases where there are typical features of IHPS on US.

Less than $60 \%$ of infants had a supporting biochemical picture in our series. The presence of alkalosis supports but does not confirm the diagnosis. In our study, $2 \mathrm{NL}$ infants had evidence of alkalosis at presentation.

The early presentation of children with IHPS may give an equivocal clinical, biochemical and radiological picture. In such circumstances, the infant should be observed and re-evaluated in 1-2 days when the lesion may become demonstrable clinically or radiologically [3]. If there is no palpable 'tumour' on a test feed, criteria for surgery should include definite diagnostic measurements by US followed by finding a palpable pyloric mass on examination under anaesthetic (EUA). In the absence of palpable mass on 
EUA, we now use upper GI endoscopy to demonstrate features of IHPS and confirm the diagnosis [19,20] before proceeding with pyloromyotomy.

Our $1 \%$ rate of NL in IHPS compares favourably with other studies. However, with the benefit of hindsight, in the 4 patients who had negative explorations, the decision to operate may have changed if we strictly adhered to the criteria of positive test feed and an 'in-house' US with definite diagnostic measurements. If these diagnostic criteria are not met, repeat investigations should be considered in order to avoid negative surgical exploration.

\section{Abbreviations}

EUA: examination under anaesthetic; GI: gastrointestinal; GOR: gastro oesophageal reflux; IHPS: infantile hypertrophic pyloric stenosis; NHS: national health service; NL: negative laparotomy; US: ultrasound scan

\section{Competing interests}

The authors declare that they have no competing interests.

\section{Authors' contributions}

$\mathrm{DM}, \mathrm{SM}$ and RS collected and analysed the data and drafted the manuscript. CB conceived of the study, and participated in its design and coordination. DM, RC, SK and DP participated in the design of the study. CB, PL and SK helped with revisions on the manuscript. All authors read and approved the final manuscript.

\section{References}

I. Teele RL, Smith EH: Ultrasound in the diagnosis of idiopathic hypertrophic pyloric stenosis. N Engl J Med 1977, 19;296(20): | | 149-50.

2. Macdessi J, Oates RK: Clinical diagnosis of pyloric stenosis: a declining art. BMJ 1993, 27;306(6877):553-5.

3. Misra D, Akhter A, Potts SR, Brown S, Boston VE: Pyloric stenosis: is over-reliance on ultrasound scans leading to negative explorations? Eur / Pediatr Surg 1997, 7(6):328-30.

4. Hulka F, Campbell TJ, Campbell JR, Harrison MW: Evolution in the recognition of infantile hypertrophic pyloric stenosis. Pediatrics 1997, 100(2):E9.

5. Tam PK, Chan J: Increasing incidence of hypertrophic pyloric stenosis. Arch Dis Child 1991, 66(4):530-I.

6. Hernanz-Schulman M, Sells LL, Ambrosino MM, Heller RM, Stein SM, Neblett WW 3rd: Hypertrophic pyloric stenosis in the infant without a palpable olive: accuracy of sonographic diagnosis. Radiology 1994, 193(3):77I-6.

7. Godbole P, Sprigg A, Dickson JA, Lin PC: Ultrasound compared with clinical examination in infantile hypertrophic pyloric stenosis. Arch Dis Child 1996, 75(4):335-7.

8. Neilson D, Hollman AS: The ultrasonic diagnosis of infantile hypertrophic pyloric stenosis: technique and accuracy. Clin Radiol 1994, 49(4):246-7.

9. Kiely EM: Commentary. Arch Dis Child 66(I):132-133. Comment to: B Zeidan, J Wyatt, A Mackersie, and R J Brereton. Recent results of treatment of infantile hypertrophic pyloric stenosis. Arch Dis Child 63(1988) 1060-1064

10. Forman HP, Leonidas JC, Kronfeld GD: A rational approach to the diagnosis of hypertrophic pyloric stenosis: do the results match the claims? J Pediatr Surg 1990, 25(2):262-6.

II. Blumhagen JD, Maclin L, Krauter D, Rosenbaum DM, Weinberger E: Sonographic diagnosis of hypertrophic pyloric stenosis. AJR Am J Roentgenol 1988, 150(6): 1367-70.
12. Philippin U, Zieger M: Sonography of hypertrophic pyloric stenosis. Statistical analysis of the values and the diagnostic criteria. Radiologe 1989, 29(8):386-90.

13. Stunden RJ, LeQuesne GW, Little KE: The improved ultrasound diagnosis of hypertrophic pyloric stenosis. Pediatr Radiol 1986, 16(3):200-5.

14. Yip WC, Tay JS, Wong HB: Sonographic diagnosis of infantile hypertrophic pyloric stenosis: critical appraisal of reliability and diagnostic criteria. J Clin Ultrasound 1985, 13(5):329-32.

15. Leahy PF, Farrell R, O'Donnell B: $\mathbf{3 0 0}$ infants with hypertrophic pyloric stenosis: presentation and outcome. Ir Med J 1986, 79(5): I | $4-6$.

16. Is ultrasound really necessary for the diagnosis of hypertrophic pyloric stenosis? Lancet. (editorial) 1988, 2I;I(8595): I I 46.

17. Perry EP, Fraser IA, Rhodes A: Ultrasound and pyloric stenosis. Lancet 1988, 13;2(8607):391.

18. Hernanz-Schulman M, Sells LL, Ambrosino MM, et al.: Hypertrophic pyloric stenosis in the infant without a palpable olive: accuracy of sonographic diagnosis. Radiology 1994, 193:77I-776.

19. De Backer A, Bove T, Vandenplas Y, Peeters S, Deconinck P: Contribution of endoscopy to early diagnosis of hypertrophic pyloric stenosis. J Pediatr Gastroenterol Nutr 1994, I 8(I):78-8I.

20. Ward E, Easley D, Pohl J: Previously unsuspected infantile hypertrophic pyloric stenosis diagnosed by endoscopy. Dig Dis Sci 2008, 53(4):946-8. Epub 2007 Oct 13

\section{Pre-publication history}

The pre-publication history for this paper can be accessed here:

http://www.biomedcentral.com/1471-2431/8/37/prepub

Publish with Bio Med Central and every scientist can read your work free of charge

"BioMed Central will be the most significant development for disseminating the results of biomedical research in our lifetime. "

Sir Paul Nurse, Cancer Research UK

Your research papers will be:

- available free of charge to the entire biomedical community

- peer reviewed and published immediately upon acceptance

- cited in PubMed and archived on PubMed Central

- yours - you keep the copyright 